\title{
In Vitro Anti-Microbial Activity of Aqueous and Ethanolic Leaf Extracts of Justicia flava and Tephrosia vogelii that grows in Uganda.
}

\author{
George Alfred Masete ${ }^{a, 1}$ \\ a School of School of BioSecurity, Biotechnical and Laboratory Sciences, Makerere University
}

Abstract

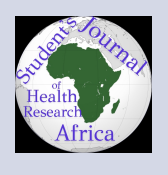

Background: ${ }^{a}$

Medicinal plants and plant-derived medicines are increasingly becoming popular in modern society as natural alternatives to synthetic chemicals due to increased resistance to drugs by microbes. There is a need to search for new active compounds to validate the medicines used traditionally. The study was carried out on the aqueous and ethanolic leaf extracts of Justicia flava and Tephrosia vogeli, to determine their antimicrobial and phytochemical profiles.

Method:

The agar well diffusion method using Mueller Hinton agar plates, to determine the diameters of the antibacterial inhibition zones of the ethanolic and aqueous extracts on standard bacterial strains of Staphylococcus aureus, Pseudomonas aeruginosa, and Salmonella spp was conducted.

Results:

Ethanol extract of Justicia flava showed activity against S. aureus and P. aeruginosa and no activity on Salmonella spp.

The aqueous extract had no activity on any of the three bacteria. However, both the aqueous and ethanol extract of $T$. vogelii showed activity on the test microbes used, and the highest activity was seen with Salmonella spp. For minimum inhibitory concentration (MIC), J. flava, P. aeruginosa had the highest value of $500 \mathrm{mg} / \mathrm{ml}$ and S. aureus showed the lowest value of $250 \mathrm{mg} / \mathrm{ml}$ whereas, with the aqueous extract of $T$. vogelii, P. aeruginosa showed the highest MIC value of $165 \mathrm{mg} / \mathrm{ml}$ and Salmonella spp the lowest of $41.25 \mathrm{mg} / \mathrm{ml}$. However, Salmonella showed a high value $(300 \mathrm{mg} / \mathrm{ml})$ with the ethanol extract and $S$. aureus the lowest $(75 \mathrm{mg} / \mathrm{ml})$. The phytochemical screening revealed the presence of saponins, terpenoids, tannins, phenolics, and reducing sugars.

Conclusions and recommendations:

This study showed that Justicia flava and Tephrosia vogelii possess antimicrobial activity and are therefore potential candidates for combating bacterial infections, especially those accelerated by S. aureus, P. aeruginosa, and Salmonella species.

\begin{tabular}{lc}
\hline \multicolumn{1}{c}{ email: } & georgemasete@gmail.com \\
recieved: & 20th/01/2021 accepted: \\
5th/02/2021 journal of microbiology
\end{tabular}

\section{Background of the study}

Infectious diseases are disorders caused by pathogenic microorganisms like bacteria, viruses, fungi, protozoa, and multicellular parasites (Sathya et al., 2012). They account for about half of the deaths in tropical countries (Khosravi et al., 2006). Today's health care systems rely largely on plant material (Patel et al., 2018). Despite recent development in the synthetic drug, chemistry, and production of antibiotics, plants still occupy an important 
role in the modern and traditional system all over the world.

Modern medicines are primarily from synthetic or plant origin while synthetic origin may have toxic effects, the plant medicines have less toxicity, and their importance is being realized in both developed and developing countries, plants are an important source of medicines and play a key role in world health (Constabel, 1990). The use of plant-based remedies is also widespread in many industrialized countries and numerous pharmaceuticals are based on or derived from plant compounds. Plant secondary metabolites were found to be sources of various phytochemicals that could be used directly or as intermediates for the production of pharmaceuticals, as additives in cosmetic, food, or drink supplements (Ong PohLiang, 2007).

The prevalence of bacterial infections is quite alarming and the effectiveness of antimicrobial chemotherapeutic agents is being compromised by several alarming trends; inappropriate prescription, use of broad-spectrum drugs instead of narrowspectrum drugs, sale of over-the -counter antimicrobial drugs in some countries, and lack of sufficient tests before the prescription. The consequences of the aforementioned trends produced more or less, foreseeable and important side effects. These side effects include toxicity, allergic reactions, disruption of normal flora, and acquisition of drug resistance by formerly sensitive microbes for example Ciprofloxacin.

It is reported that one out of ten medical cases is related to a medicine's adverse effect. Thus, the future effectiveness of antimicrobial therapy is in doubt. Hence, there is a need for an alternative means to treat infections. Great interest has developed in searching for antimicrobial drugs from natural plant products and this interest arises from the belief that drugs derived from plants are safe and dependable, compared to synthetic drugs (Viswanathan et al., 2009).

According to Wilem (2008), Justicia flava, a member of the Acanthaceae family is a perennial herb or shrublet, growing up to $450 \mathrm{~mm}$ high. The leaves are lanceolate or broadly ovate (egg-shaped), opposite, simple, entire, and the leaf stalk is about 1-25 $\mathrm{mm}$ long. The flowers are in a terminal inflorescence and are subtended by large, leaf-like bracts. The roots and the leaves are used in ethnomedicine to treat fever, coughs, kidney problems, and stom- ach discomfort. This plant contains complex active components that are pharmacologically

Tephrosia vogelii is a small African leguminous tree, can also be used as a medicine for skin diseases and internal worms. Traditionally, it is used as a fish poison, although this is now illegal in many countries because of the poison in the leaves and seeds (rotenone). The biological activities are due mainly to rotenoids isolated from the plant (Dzenda et al., 2008).

A decoction of roots is given in dyspepsia, diarrhea, rheumatism, asthma, and urinary disorders; roots gave with black pepper in colic. A liniment prepared from the roots is used in elephantiasis (Yedjou, 2013).

Pulverized roots smoked for relief from asthma and cough, a decoction of pods used as a vermifuge and to stop Vomiting. Seeds yield oil said to be specific against scabies, itch, eczema, and other skin eruptions Fresh root-bark, ground and made into a pill, with a little black pepper, is frequently given in cases of obstinate colic. (Yedjou et al., 2013). Tephrosia, vogelii has a great potential in the therapy of animal and human diseases (Salemink, 1980).

There is reduced antimicrobial activity associated with some groups of synthetic drugs with the widespread occurrence of multidrug-resistant strains of organisms. The prohibitive cost of the drugs and chemicals as well as sometimes weakly regulated use has greatly enhanced this occurrence. This has caused a major global public health concern for animal and human health care. There is therefore urgent need to explore other possible alternative compounds and chemicals, including natural products from plants.

\section{Methodology \\ Study design}

This was an experimental study design that involved both qualitative and quantitative approaches. The phytochemical analysis of the plant extracts using standard test was qualitative whereas the antibacterial screening of the extracts using the agar well diffusion method was quantitative because the zones of inhibition were measured using a ruler. Strains of Staphylococcus aureus, Pseudomonas aeruginosa, and Salmonella were used as test microbes in the study. Agar well diffusion method was used in the determination of 
the antimicrobial activity and minimum inhibitory concentration of the two extracts.

\section{Study site}

The study was carried out in the following places at Makerere University, microbiology laboratory, department of parasitology and microbiology, and pharmacology and toxicology Laboratory, College of Veterinary Medicine, Animal Resources and Biosecurity.

\section{Medicinal plant selection criteria}

The plant selection was based on ethnobotanical knowledge which is rich in traditional uses of the plants for treating various ailments, the relatively little scientific research done on the plant despite its numerous blind traditional uses also influenced their selection.

\section{Plant collection and identification}

The leaves of the plants were collected from Naro Mbarara, and Nsibirwa grounds near the botanical gardens in Makerere University in a dark polyethylene bag and transported to Makerere University Herbarium where it was identified by a Botanist. Voucher specimen numbers obtained and specimens deposited in the herbarium for future reference.

\section{Preparation of plant materials for extraction}

The leaves of the two selected plants were washed under running tap water to remove any dirt. The clean leaves were then air-dried (Serunjogi et al., 2020) in the laboratory and the dried plant material will be ground using an electric grinder, and the weight determined using a weighing balance.

\section{Preparation of Extract:}

The plant leaves of the selected plants were collected from Makerere University and dried. The shade dried leaves were powdered using an electric grinder. About 117g of dried powder of J. flava and $100 \mathrm{~g}$ of $T$. vogelii were cold macerated in $1000 \mathrm{mls}$ and $3000 \mathrm{mls}$ respectively with $70 \%$ ethanol and soaked for 72 hours. While for aqueous extraction, 100g and 50g of J. flava and T.vogelii respectively were boiled in 1.5litre and 1.5litres of water for 45 minutes, filtered then dried in an oven at 50 degrees for 24 hours. This was done to remove coarse particles.

The resultant filtrate was concentrated by evaporating water using the rotary evaporation method at $100^{\circ} \mathrm{C}$ to remove the excess water from the extract. The solid extract was stored at $4^{\circ} \mathrm{C}$ in the refrigerator and used in the study.

\section{The concentration of the extracts}

The filtrate was concentrated using Rotary Evaporator at $50{ }^{\circ} \mathrm{C}$ at Natural Chemotherapeutic Research Institute (NCRI) and the resultant solution was oven-dried at $50^{\circ} \mathrm{C}$. The dry residue was weighed using an analytical weighing balance, transferred into clean bottles, and stored in a refrigerator at $4^{\circ} \mathrm{C}$. Determination of percentage yield was done using the formula below;

$$
\begin{gathered}
\begin{array}{c}
\% \text { Yield }= \\
\text { Weight of the dry residue }
\end{array} \\
\text { Weight of the powder soaked } \\
\text { in } 70 \% \text { Ethanol (200g). }
\end{gathered}
$$

\section{Preparation of stock solution}

At every treatment, a fresh solution was prepared by weighing $1 \mathrm{~g}$ of the extract and dissolving it in $10 \mathrm{mls}$ of distilled water to give a stock solution whose concentration was $100 \mathrm{mg} / \mathrm{ml}$.

\section{Microbial samples}

Different multi-drug resistant strains of (Staphylococcus aureus, Pseudomonas aeruginosa, Salmonella typhi were obtained from microbiology laboratory, department of parasitology and microbiology, College of Veterinary Medicine, Animal Resources and Biosecurity, Makerere University. These bacteria served as test pathogens for antibacterial activity assay.

\section{Culture media, antibiotics, and reagents}

Mueller-Hinton agar media purchased at local suppliers used in the experiment to culture the organisms. The phytochemical reagents included: ferric chloride, hydrochloric acid-Meyers reagent, (98\%) sulphuric acid, (50\%) methanol, $25 \%$ ammonia was used in the identification of phytochemical constituents of the plant extractives. Peptone water and Muller Hinton agar were used for MIC and Distilled water as the solvent during the extraction process in the preparation of the crude extract. Antibiotic: Cipro and Distilled water were used as positive and negative controls respectively because Cipro has a broad-spectrum against the selected bacteria.

\section{Preparation of culture media}

Muller Hinton agar (Biotech, UK), which is recommended for carrying out antimicrobial susceptibility test for rapid growing organisms such as; Staphylococcus aureus was used (Washington, 1970).

19 grams Mueller-Hinton agar was weighed and transferred into a conical flask containing $500 \mathrm{ml}$ of distilled water. The mixture will be sterilized by steaming at $121^{\circ} \mathrm{C}$ for 15 minutes, then later allowed to cool at $50^{\circ} \mathrm{C}$. About $20 \mathrm{mls}$ of the medium 
was dispensed into the Petri dishes and left to set. The agar plates were incubated for 24 hours at $37^{\circ} \mathrm{C}$ to confirm sterility. If no growth occurred, then the plates were considered sterile.

\section{Antimicrobial Activity Test Using the Agar Well Diffusion Method}

\section{Agar well diffusion method}

This was carried out using Mueller- Hinton agar plates. The Mueller- Hinton agar was placed in Petri-dishes after autoclaving at $121^{\circ} \mathrm{C}$ and allowed to cool and solidify. One to two colonies of the test organisms were respectively suspended in $5 \mathrm{ml}$ of peptone water using sterile swabs. Thereafter, uniformly inoculated onto the agar surface.

With sterile agar borers, three wells were dug in the Mueller-Hinton plates. Three hundred (300mg) of plant extract was dissolved in dimethyl sulfoxide (from a stock solution) which were filled in the wells thereafter and allowed to stand. The plates were then be incubated at $37^{\circ} \mathrm{C}$ for 24 hours, then examined for the presence of zones of inhibition. For the positive extracts, the zones of inhibition were measured using a ruler and expressed in millimeters. Using the same procedures, both the positive and negative control experiments were set up. For the positive control, Ciprofloxacin was used.

Determination of minimum inhibitory concentration (MIC) by serial dilution method.

The MIC values were determined by using two dilutions of the stock extract solution in bacterial broth. Four test tubes were arranged in arrow and two-fold serial dilutions of the extracts were carried out with $500 \mathrm{mg}$ per $\mathrm{ml}$ and $300 \mathrm{mg}$ per $\mathrm{ml}$ as the highest dilutions for J. flava and $T$. vogelii respectively, $50 \mathrm{mg} / \mathrm{ml}$ of Cipro

\section{Positive and negative controls}

Cipro was used as a positive control because of its broad spectrum and distilled water used as a negative control

\section{Phytochemical analysis}

The crude aqueous extracts and ethanolic were subjected to a standard phytochemical test for the presence or absence of the following phytochemicals: saponins, flavonoids, glycosides, alkaloids, tannins, terpenoids and reducing sugars, and starch.
The aqueous and ethanolic leaf extract of Justicia flava and Tephrosia vogelii were analyzed for the presence of tannins, saponins, terpenoids, glycosides, steroids, phenolic compounds, flavonoids, and starch.

\section{a) Test for tannins}

To the two $\mathrm{ml}$ of the extract $2 \mathrm{ml}$ of $5 \%$, ferric chloride was added, the formation of yellow-brown precipitate indicated the presence of tannins.

\section{b) Test of Saponins}

To the $0.5 \mathrm{ml}$ of filtrate $5 \mathrm{ml}$ of distilled water will be added, frothing indicated the presence of Saponins.

\section{c) Test for Terpenoids}

To the $2 \mathrm{ml}$ of extract $5 \mathrm{ml}$ of chloroform was added followed by the addition of $3 \mathrm{ml}$ concentrated sulphuric acid. The reddish-brown color indicated the presence of terpenoids.

\section{d) Test for Glycosides}

About $1 \mathrm{ml}$ of the extract was dissolved in $1 \mathrm{ml}$ of glacial acetic acid containing one drop of ferric chloride solution. This was then under-layered with $1 \mathrm{ml}$ of concentrated sulphuric acid. A brown ring was indicative of the presence of glycosides.

\section{e) Test for Steroids}

To the $0.5 \mathrm{ml}$ of filtrate, $2 \mathrm{ml}$ acetic anhydride was added followed by the addition of $3 \mathrm{ml}$ Concentrated sulphuric acid. Blue-green ring indicated the presence of Steroids.

\section{f) Test for Phenolics}

To the $2 \mathrm{ml}$ of extract, $1 \mathrm{ml}$ of $1 \%$ ferric chloride was added, blue or green color indicated the presence of Phenolics.

\section{g) Test for Flavonoids}

To one $\mathrm{ml}$ of the extract, a few drops of dilute sodium hydroxide were added. An intense yellow color production in the plant extract, which becomes colorless on the addition of a few drops of dilute acid indicated the presence of flavonoids.

\section{h) Test for Starch}

To the extract drops of iodine solution were added, the formation of blue color was indicating the presence of starch.

\section{Quality assurance}

The experiment had negative and positive control groups which were used for reference. All the tests were done in triplets to ensure precision. Accuracy was ensured when taking any measures to ensure reliable results. Data obtained were recorded in a book on a hard copy to be used for analysis. 
Table 1. Interpretation of phytochemical profile data

Symbol Meaning

- Not present

+ Present

\section{Data analysis}

Data of antimicrobial activity was recorded as zones of inhibition in millimeters. These were then used to calculate average zones of inhibition presented as means SD and differences between concentrations will be calculated using one-way ANOVA and student's t-test. A phytochemical screening result was presented qualitatively for the presence or $a b$ sence of compounds as indicated by color changes.

\section{Ethical consideration}

All proceedings in the laboratory were handled according to the International Biosafety Guidelines (Laboratory Biosafety Guidelines, 2004). The experimental procedure was approved by the Department of Veterinary Microbiology, Comparative Medicine \& Clinics at COVAB. The project was carried out under the authorization of the college undergraduate committee.

\section{Limitation of the study}

Lack of capacity to determine which particular phytochemical is responsible for the plant's antibacterial activity, the solvents used in extraction could not extract all the potent phytochemicals in the plants and also Bacterial strains that have been stored for long tend to be more susceptible to antibacterial agents and this may interfere with results.

\section{RESULTS}

\section{Data presentation}

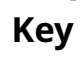

$+P$ resent

- Absent

Key

+ Weakly present

\section{- Absent}

For Justicia flava (yellow flava) both the aqueous and ethanolic leaf extracts contained; Saponins, Tannins, Terpenoids, and Phenolics. With reducing sugars only present in the aqueous extract. T. vogelii contained Saponins, Tannins, and Phenolics and reducing sugars in the aqueous extract and didn't contain Terpenoids in the ethanol extract. Glycosides and starch were not detected in any of the extracts for both plants i.e. J. flava and T. Vogelii.

Of the total compounds tested for, both the aqueous and ethanol extract of both plants contained five compounds of those tested for as shown in graphs above. Four compounds were common to both the aqueous and ethanolic extract for both plants i.e. saponins, tannins, reducing sugars, and phenolics. Of the seven compounds tested for, two were absent in both the aqueous and ethanolic extract for both plants.

Zone diameters of inhibition decreased with increased dilution I,e $\frac{1}{2}, 1 / 4,1 / 8,1 / 16$.and $1 / 32$.and the concentration next to where no growth occurred was considered the MIC of the extract.

Figure 2.0 Graph of mean diameters of the zones of inhibition for justicia flava.

\section{MINIMUM INHIBITORY CONCENTRATION} (MIC)

The Minimum inhibitory concentrations of the extracts were measured and results recorded in the tables shown below;

KEY: ND $=$ Not done

KEY: ND $=$ Not done

Only the extracts that showed activity were further used to determine the minimum inhibitory concentration values and those whose MIC values were not determined are indicated as ND in the table above in table 3, the MIC values are quite higher as compared to the standard drug (Cipro) this indicates that J. flava is less potent and has efficacy. However, the results for $T$. vogelii shown in table 4 indicates high efficacy and potency as compared to Cipro. The lowest MIC value was observed with salmonella spp (41.25) and the highest was $300 \mathrm{mg} / \mathrm{ml}$ 
Table 2. Results of the qualitative phytochemical analysis of the crude extracts for J.flava

\begin{tabular}{lll}
\hline \multirow{2}{*}{ Compound } & \multicolumn{2}{l}{ Plant Extracts used } \\
& Aqueous & Ethanol \\
Saponins & + & + \\
Tannins & + & + \\
Reducing sugars & + & - \\
Terpenoids & + & + \\
Phenolics & + & + \\
Starch & - & - \\
Glycosides & - & - \\
\hline
\end{tabular}

Table 3. Results of the qualitative phytochemical analysis of the crude extracts for T.vogelii

\begin{tabular}{lll}
\hline Compound & Aqueous extract & Ethanol extract \\
Saponins & + & + \\
Tannins & + & + \\
Reducing sugars & + & + \\
Terpenoids & + & - \\
Phenolics & + & + \\
Starch & - & - \\
Glycosides & - & - \\
\hline
\end{tabular}

\section{Aqueous extrract only}

Ethanol extract only

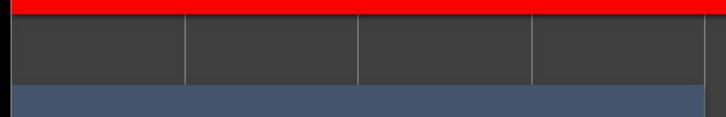

-

Both
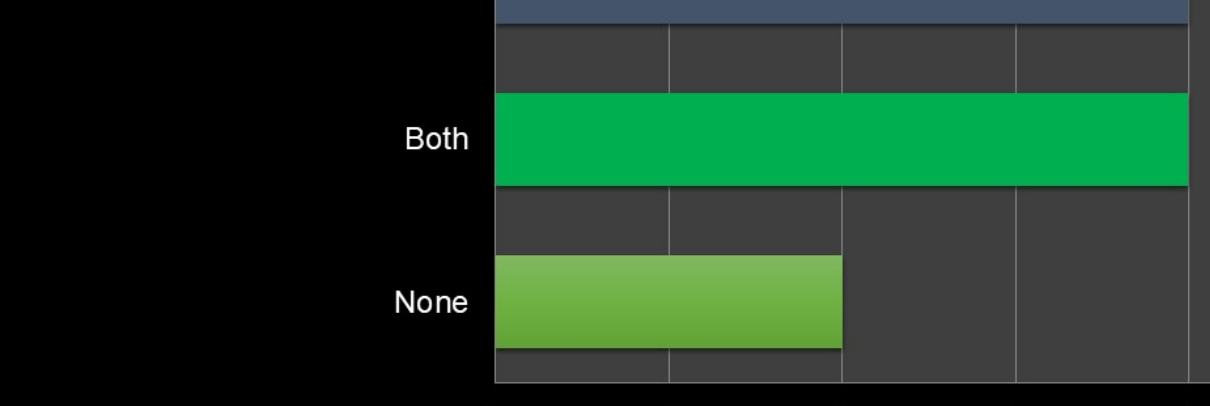

0

1

2

3

4

None $\quad$ Both $\quad$ Ethanol extract only $\quad$ Aqueous extract only

Chart 1. Graph showing the phytochemical profile of aqueous and ethanolic leaf extracts of Justicia flava 


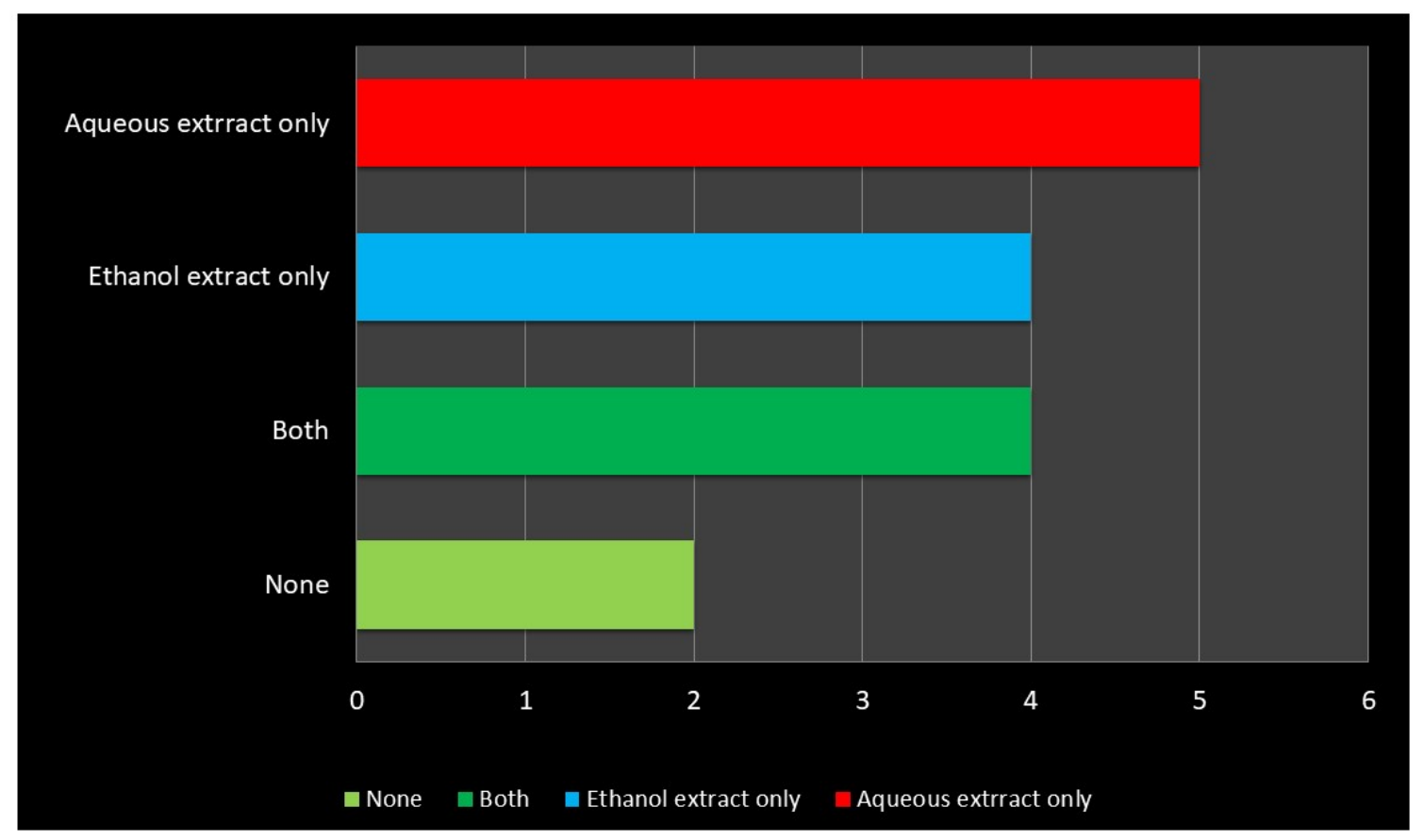

Chart 2. Graph showing the phytochemical profile for the aqueous and ethanolic leaf extracts of Tephrosia vogelii

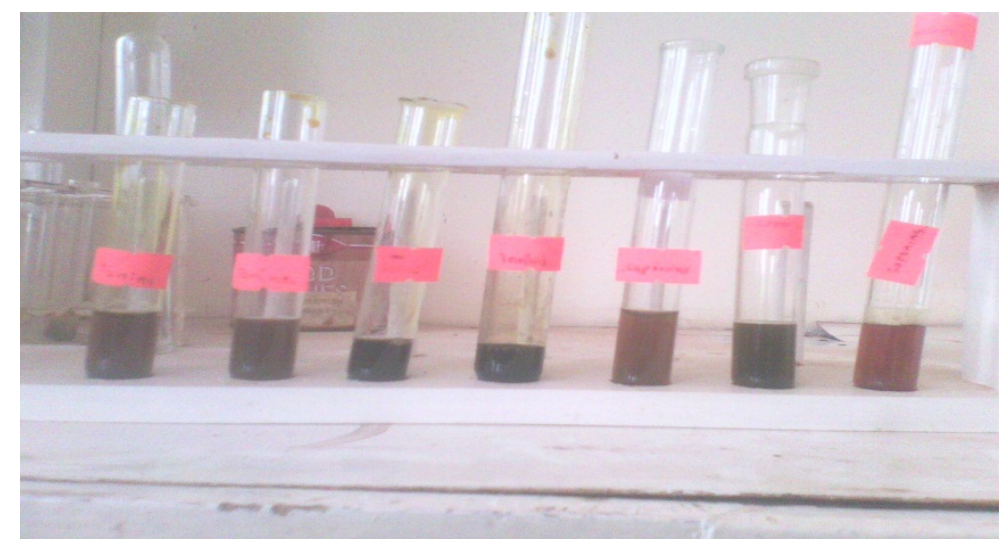

Figure 1. Phytochemical results for aqueous extract (J.flava)

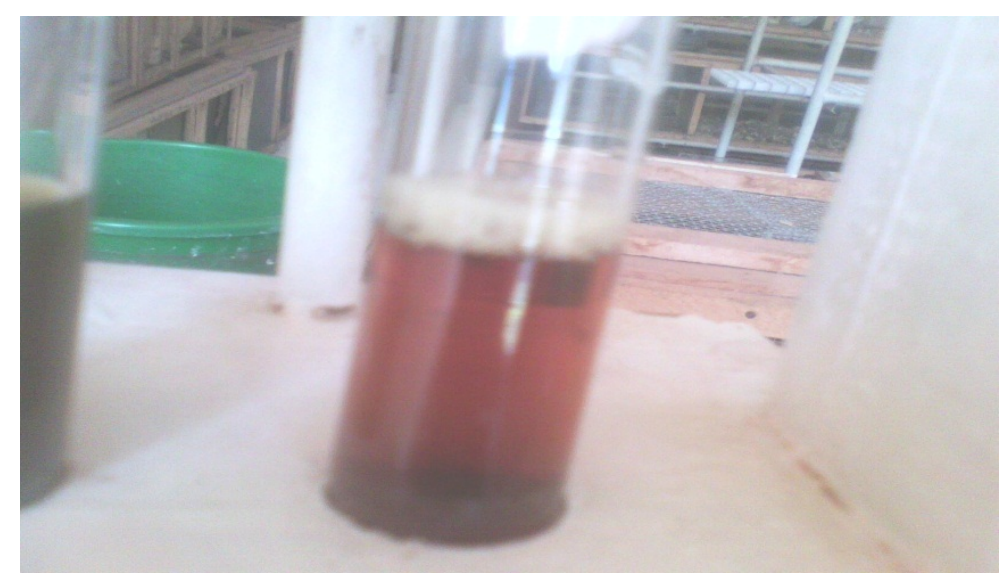

Figure 2. Saponins present (aqueous extract of $J$. flava) 


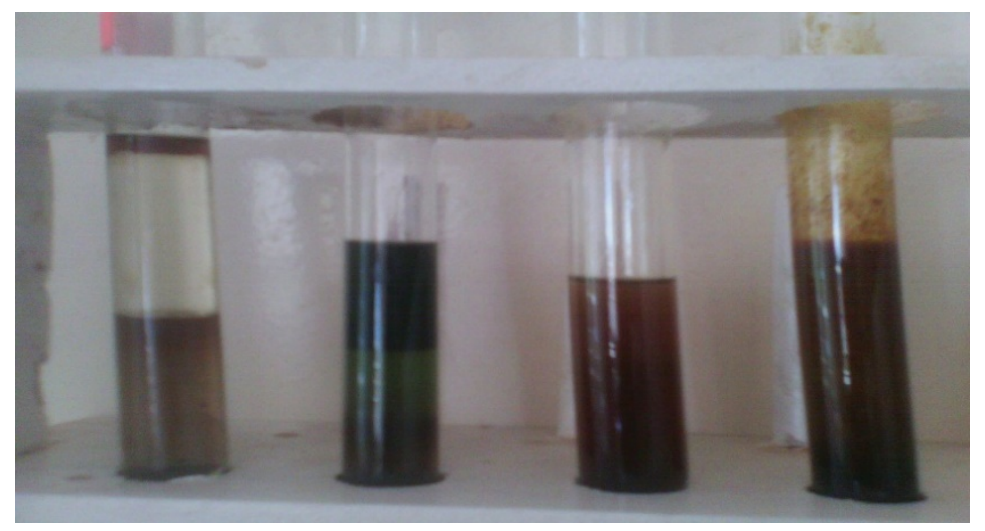

Figure 3. terpenoids present (aqueous extract of J.flava)

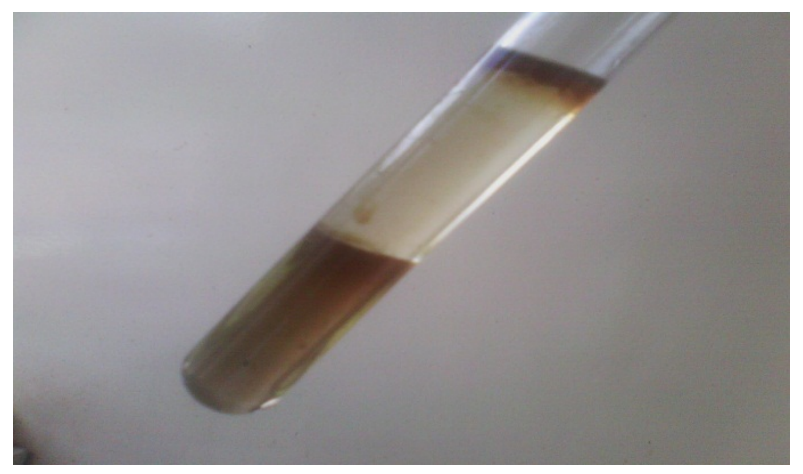

Figure 4. positive results for terpenoids (J.flava)

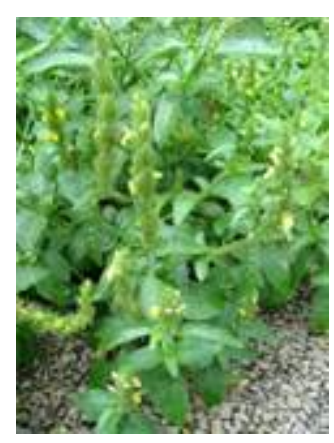

Figure 5. image of image picture of Tephrosia vogelii plant. (vahl vahl)

Table 4. Diameters $(\mathrm{mm})$ of the zones of inhibition of flava

\begin{tabular}{|c|c|c|c|c|c|c|c|c|c|}
\hline \multirow[t]{2}{*}{ Extracts/Drugs } & \multicolumn{9}{|c|}{$\begin{array}{l}\text { Microorganisms and the diame- } \\
\text { ters of their zones of inhibition } \\
d 1, d 2 \text { and } d 3(\mathrm{~mm})\end{array}$} \\
\hline & \multicolumn{3}{|c|}{$\begin{array}{l}\text { Staphylococcus } \\
\text { aureus }\end{array}$} & \multicolumn{3}{|c|}{$\begin{array}{l}\text { Pseudomonas } \\
\text { auriginosa }\end{array}$} & \multicolumn{3}{|c|}{$\begin{array}{l}\text { Salmonella } \\
\text { typhi }\end{array}$} \\
\hline Aqueous & 0 & 0 & 0 & 0 & 0 & 0 & 0 & 0 & 0 \\
\hline Ethanol & 13 & 12 & 13 & 13 & 12 & 13 & 0 & 0 & 0 \\
\hline Drug (Cipro) & 38 & 40 & 40 & 40 & 38 & 39 & 38 & 40 & 40 \\
\hline DMSO & 0 & 0 & 0 & 0 & 0 & 0 & 0 & 0 & 0 \\
\hline
\end{tabular}




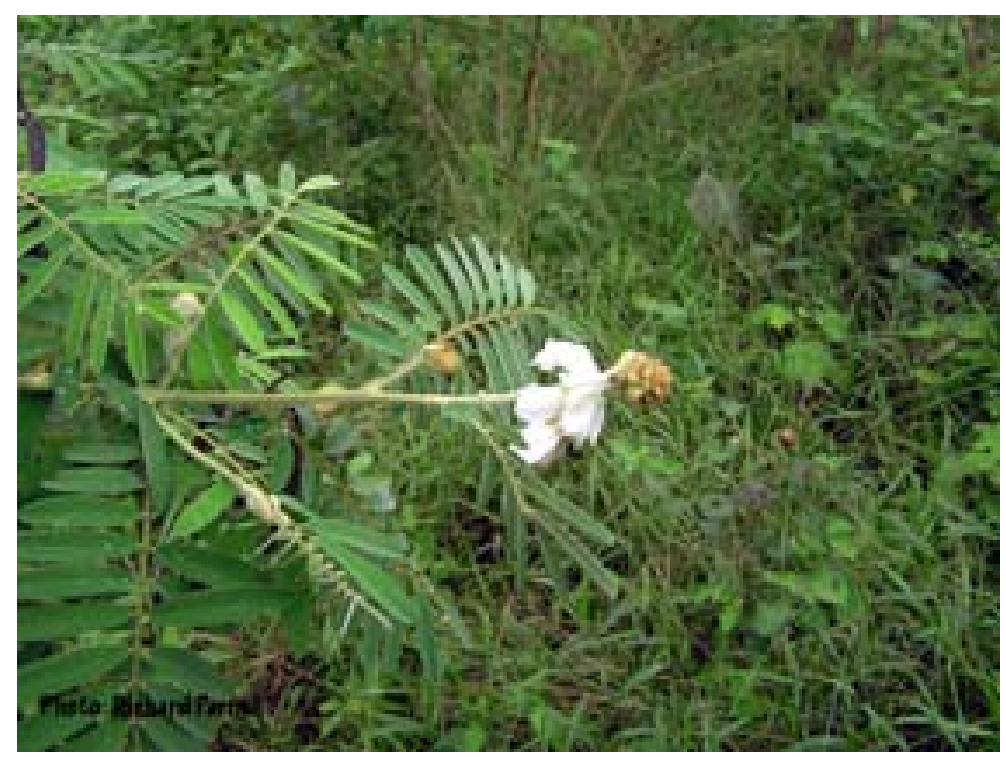

Figure 6. image of Tephrosia vogelii plant.

Figure 7. showing a zone of inhibition of the plantextract on salmonella spp

Table 5. Diameters ( $\mathrm{mm}$ ) of the zones of inhibition of Tvogelii.

\begin{tabular}{|c|c|c|c|c|c|c|c|c|c|}
\hline \multirow[t]{2}{*}{ Extracts/Drugs } & \multicolumn{9}{|c|}{$\begin{array}{l}\text { Microorganism and the diame- } \\
\text { ters of their zones of inhibition } \\
d 1, d 2 \text { and } d 3(\mathrm{~mm})\end{array}$} \\
\hline & $\begin{array}{l}\text { locc } \\
\text { aur }\end{array}$ & $\begin{array}{l}\text { Stap } \\
\text { ccus } \\
\text { us }\end{array}$ & & $\begin{array}{l}\text { don } \\
\text { aer }\end{array}$ & $\begin{array}{l}\text { Ps } \\
\text { onas } \\
\text { gino }\end{array}$ & & \multicolumn{3}{|c|}{$\begin{array}{l}\text { Salmonella } \\
\text { typhi }\end{array}$} \\
\hline Aqueous & 11 & 11 & 10 & 11 & 11 & 12 & 13 & 12 & 13 \\
\hline Ethanol & 11 & 11 & 10 & 13 & 12 & 13 & 13 & 12 & 13 \\
\hline Drug (Cipro) & 38 & 40 & 40 & 40 & 38 & 39 & 38 & 40 & 40 \\
\hline DMSO & 0 & 0 & 0 & 0 & 0 & 0 & 0 & 0 & 0 \\
\hline
\end{tabular}




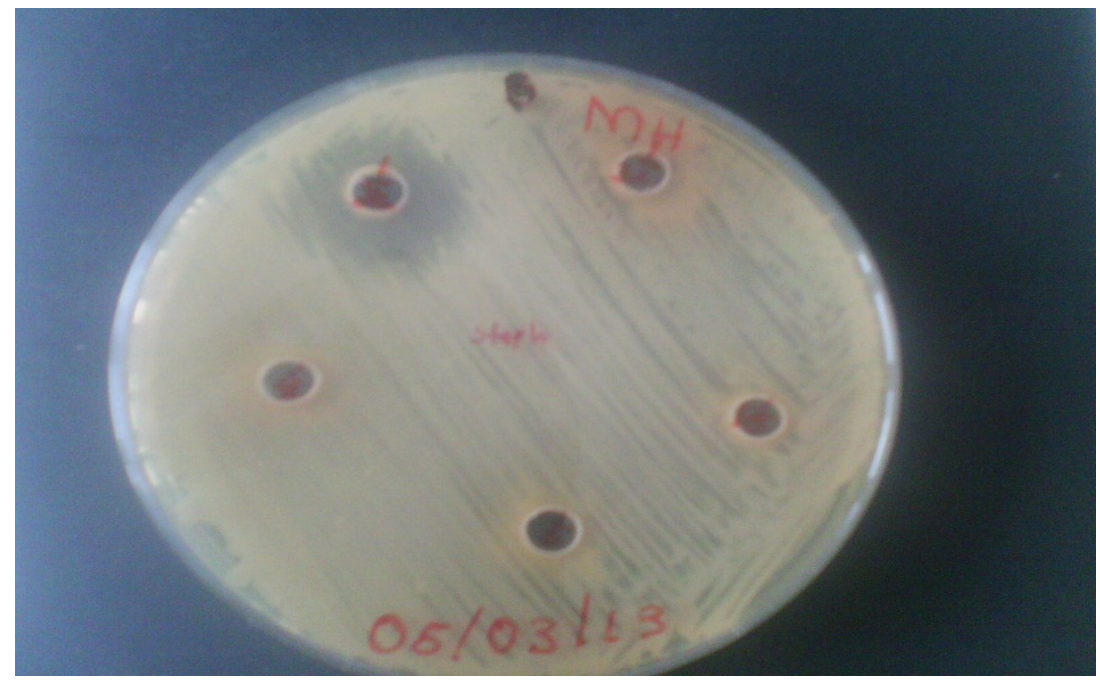

Figure 8. Result for MIC done on MH agar (S.aureus)for Tephrosia vogelii.

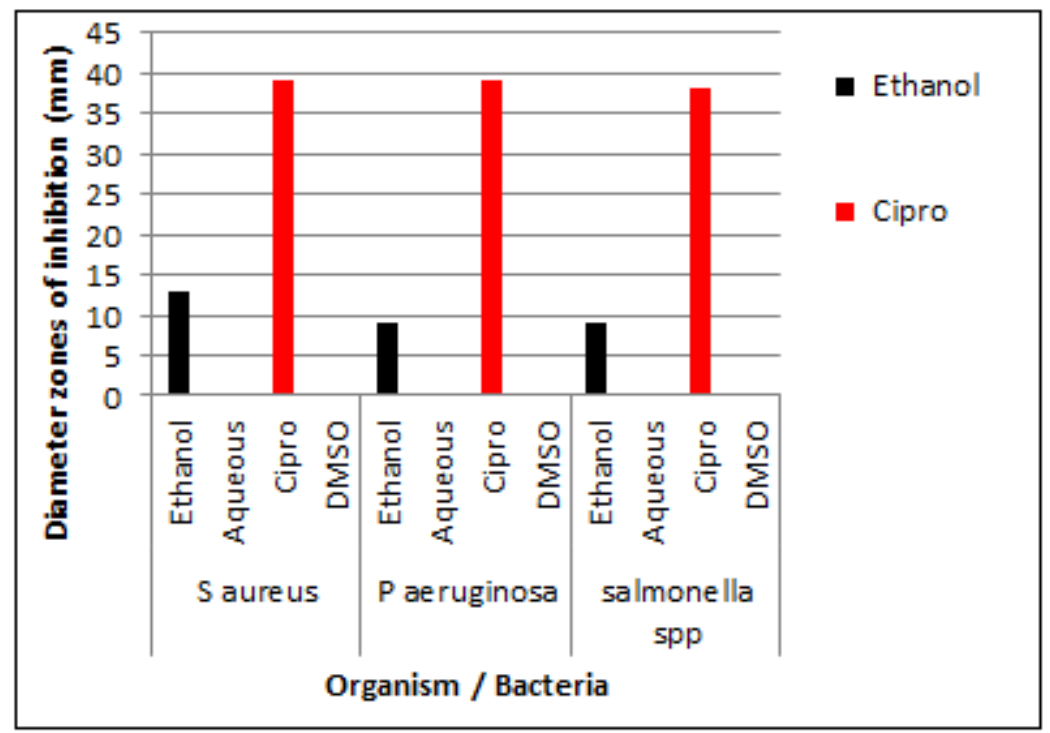

Figure 9. Graph of mean diameters of the zones of inhibition for justicia flava

Table 6. The MIC (mg/ml) forj flava extracts

\begin{tabular}{lllll}
\hline Test microorganisms used & Aqueous & Ethanol & Cipro (positive control) & DMSO (Negative control) \\
Staph.aerues & ND & 250 & 125 & 0 \\
Pseudomonas aeruginosa & ND & 500 & 125 & 0 \\
Salmonella spp & ND & ND & 50 & 0 \\
\hline
\end{tabular}

Table 7. The MIC $(\mathrm{mg} / \mathrm{ml})$ for T. vogelii extracts

\begin{tabular}{lllll}
\hline Test microorganisms used & Aqueous & Ethanol & Cipro (positive control) & DMSO (Negative control) \\
Staph.aerues & 82.5 & 75 & 125 & 0 \\
Pseudomonas aeruginosa & 165 & 150 & 125 & 0 \\
Salmonella spp & 41.25 & 300 & 50 & 0 \\
\hline
\end{tabular}




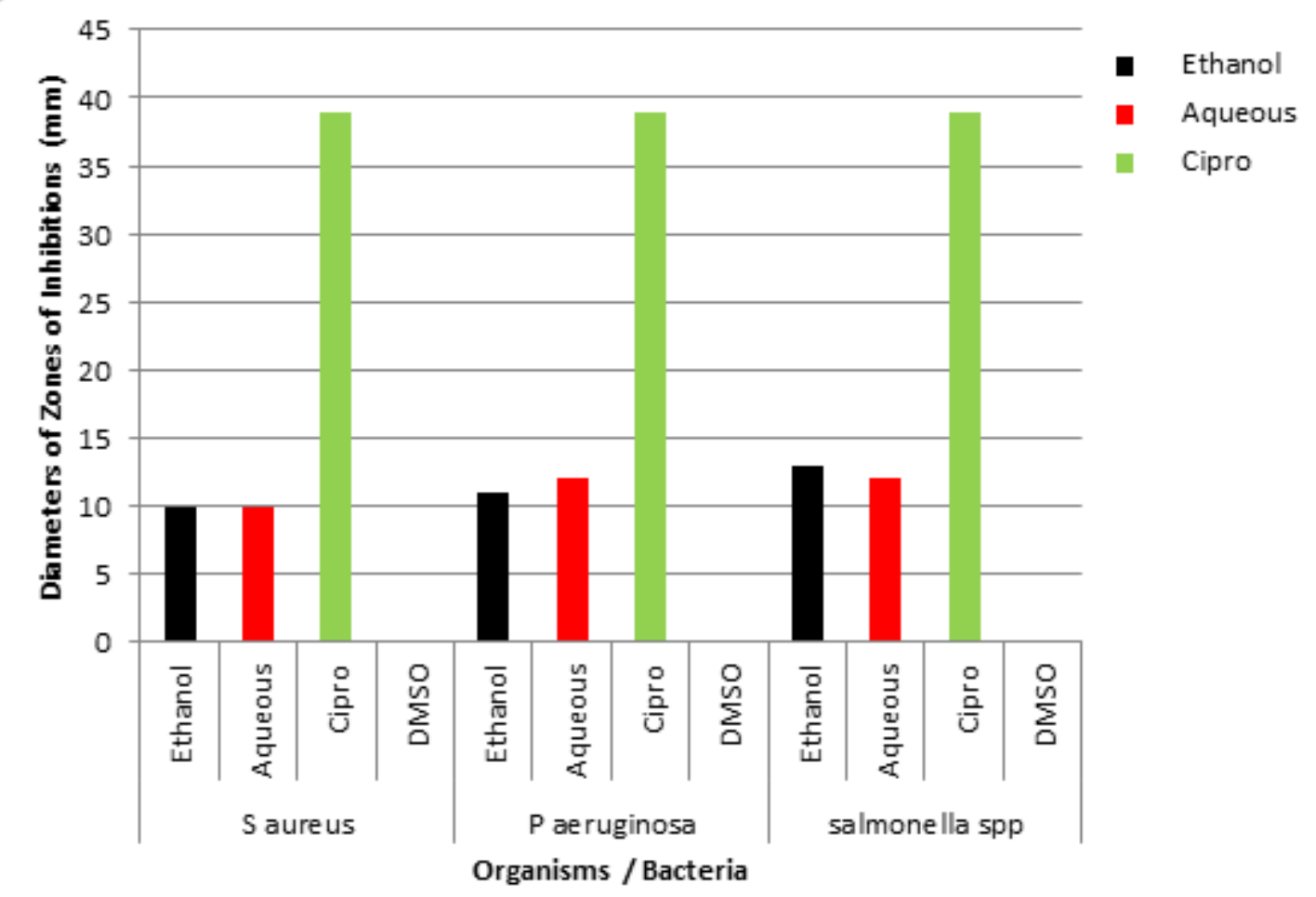

Figure 10. Graph of mean diameters of the zones of inhibition for Tephrosia vogelii

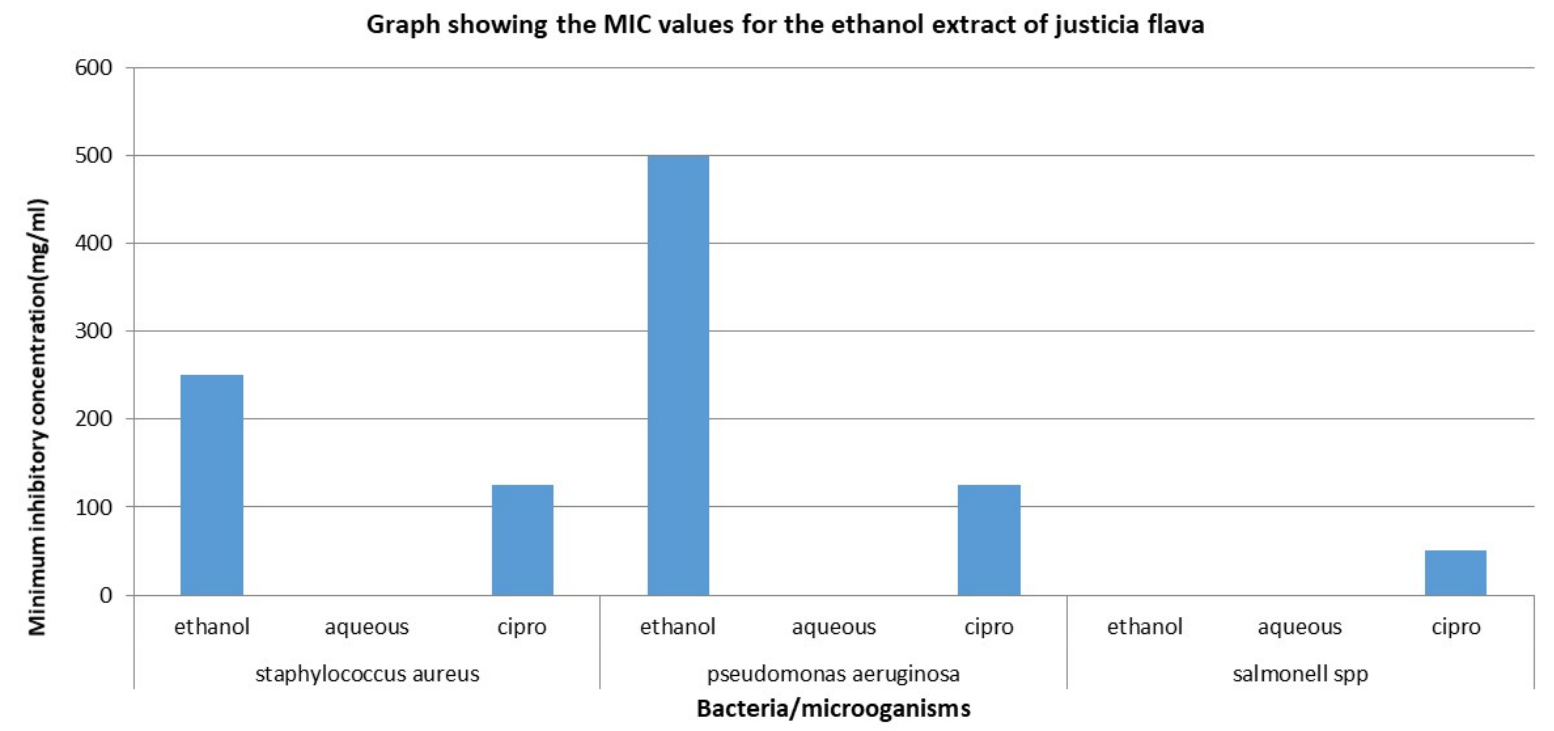

Chart 3. Showing the mic values for the ethanol extract of Justica flava. 


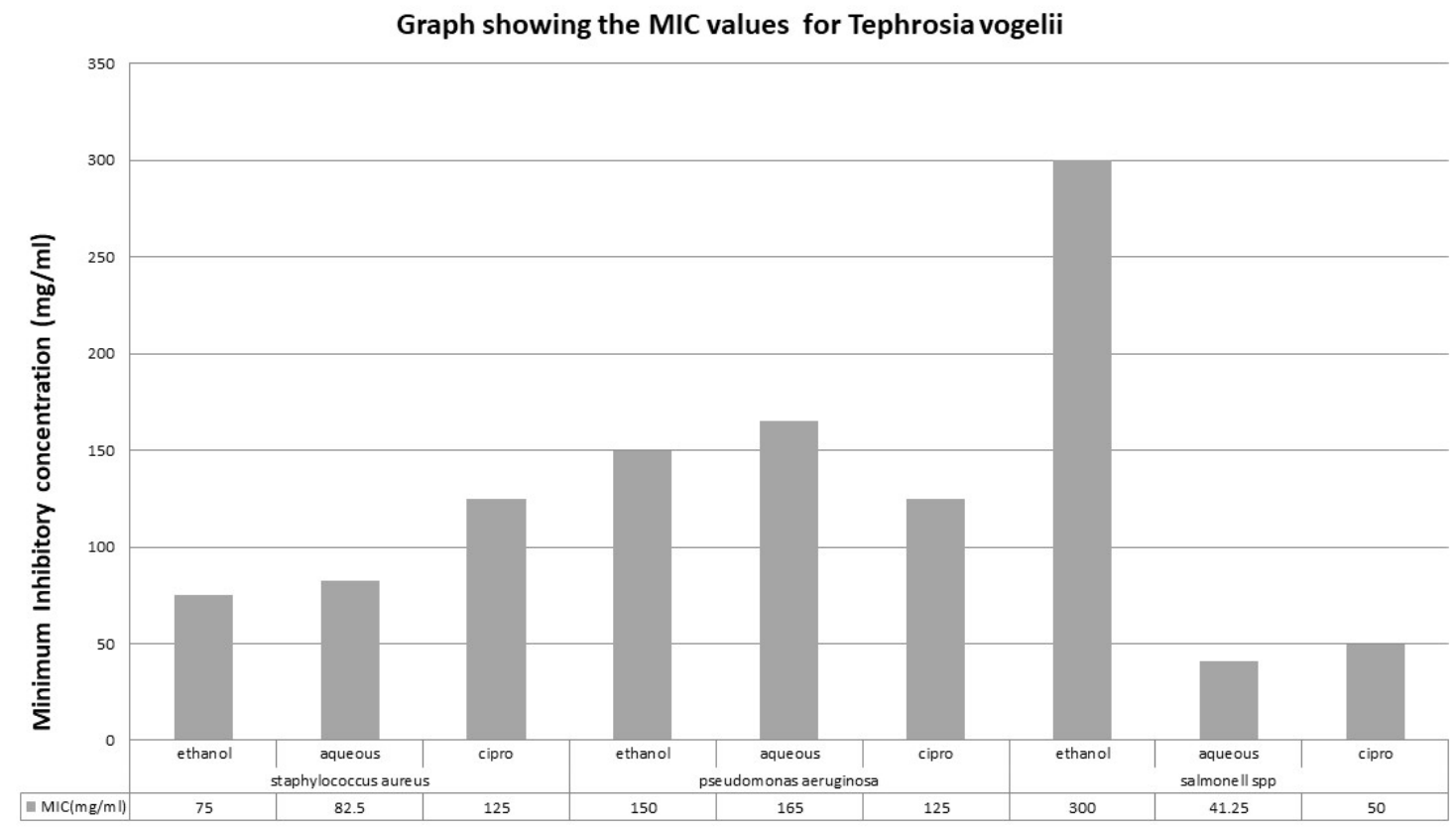

Chart 4. Showing mic values for Tephrosia vogeli

\section{DISCUSSION OF THE RESULTS; 8 Discussion}

The results obtained from this study aid in invalidating claims by traditional medicine of its therapeutic benefits. The tests carried out to confirm that Justicia flava and Tephrosia vogelii possess antibacterial activity, measured by the diameter of the zone of inhibition as well as several phytochemicals. According to the mean of clearance values and significances obtained, the susceptibility of the microorganisms to the extract of T.vogelii was in the order; Salmonella spp, Staphylococcus aureus and P.aeruginosa. This agrees with the traditional use of these plants in the management of typhoid fever, diarrhea, skin infections Abscess, food poisoning, toxic shock syndrome (Warren Levinson, 2008).

Results from this study showed that extracts obtained from aqueous solutions did not have any inhibitory effect on the bacteria, a result that is in agreement with a study by Serunjogi et al., (2020), who reported that extracts obtained from the Guava tree leave using water as the extraction solvent has no microbiological activity against bacteria.

Pseudomonas aeruginosa in this study has shown to be inhibited by plant extracts with clear zones of inhibition, a result that does not agree with a study by Serunjogi et al., (2020), which reported that the bacteria were resistant to plant origin extracts. This could be due to the difference in the extraction solvent used. Results of this study are obtained using ethanol as the extraction solvent as compared to methanol used by Serunjogi et al., (2020) when extracting from the Guava tree leaves.

This study has shown that Glycosides are absent when aqueous and ethanol are used in the extraction, a finding that partly disagrees with a study by Serunjogi, (2020) that reported the phytochemical can be extracted using water and methanol. Also, this study shows that Terpenoids has present when water is used in the extraction a result that also disagrees with a study by Serunjogi, (2020) that confirmed its presence. This could be explained by the difference in the methodology to confirm the phytochemicals. This study used $5 \mathrm{mls}$ of chloroform and $3 \mathrm{mls}$ of sulphuric acid as compared to the previous study that used $2 \mathrm{mls}$ of chloroform and $2 \mathrm{mls}$ of sulphuric acid. This is subject to further investigation.

In comparison with the drug ciprofloxacin (Cipro) which is a pure mono compound, the extracts of these plants consist of a variety of different compounds which include among others, Saponins, Tannins. Reducing sugars, Terpenoids, and Phenolics found in both the aqueous and ethanolic leaf extracts of both J flava and $T$ vogelii. These compounds confer different therapeutic proper- 
ties upon the plants. This agrees with the studies on the Ethanolic extract of $J$. adhatoda a sister plant to J.flava that revealed that the antibacterial activity against gram-positive bacteria in this case $S$, aureus is due to the presence of flavonoids, alkaloids, or polysaccharides and polypeptides (Brantner and Chakraborty, 1998). Unlike the drug in which, a single compound possesses antibacterial activity. These plants derive their properties from a combination of different compounds, each contributing and probably having a synergic effect. However, further analysis of a pure compound from these plants or their derivatives may yield equally good or even better results.

\section{Conclusion}

The antibacterial screening and the phytochemical analysis of these two plants show that they possess and contain antibacterial activity and a wide range of groups of compounds as indicated by the diameters of the zones of inhibition against $S$. aureus ATCC 25923, P. aeruginosa, and S.typhi (isolated from the laboratory).

\section{Limitations.}

Lack of capacity to determine which particular phytochemical is responsible for the plant's antibacterial activity.

Lack of capacity to carry out quantitative phytochemical analyses to determine how many of each component is present.

\section{Recommendations}

Since in vitro susceptibility testing does not guarantee the clinical efficacy of the antimicrobial agent tested, even with some positive results, further investigations to aid in the development of novel antibiotics should be done.

Further studies should be done especially on J.flava to investigate other areas that were not covered by this research, for example, to determine which particular compounds are responsible for its activity, safety, and toxicity tests since fewer publications have been made

More scientific research should be done to validate all claims by traditional healers on the therapeutic research capability of the plants used in the treatment of various disease conditions.

\section{References:}

1) Brantner A.H., Chakraborty A. (1998). In vitro antibacterial activity of alkaloids isolated from Adhatoda vasicaNEES. Pharm. Pharmacol.Lett. 8: 137139.

2) Constabel F. (1990) Medicinal plant biotechnology. Planta Med, 5(6), 421-425. https://doi.org/10.1 055/s-2006-961002 PMid:2077546

3) CORREA., Geone. M. (2012). Chemical constituents and biological activities of species of Justicia: a review. Rev. Bras. Farmacogn. [Online]. 2012, vol.22, n.1 [cited 2012-12-11], pp. 220-238. https:// doi.org/10.1590/S0102-695X2011005000196

4) Dzenda, T., Ayo, J. O., Adelaiye, A. B., \& Adaudi, A. O. (2008). Ethnomedical and veterinary uses of Tephrosia vogelii Hook F (Fabaceae): a review. Australian Journal of Medical Herbalism, 20(2), 71+. https://doi.org/10.4314/nvj.v28i3.3564

5) Khosravi, A., \& A. Behzadi., (2006). Evaluation of the antibacterial activity of the seed hull of Quercus barantii on some gram-negative bacteria. Pak. J. Med. Sci., 22: 429-432.

6) OngPoh Liang (2007) Micro propagation and callus culture of PhyllanthusniruriL, phyllanthus urinaria Land Phyllanthusmyrtifoliusmoon (euphorbiaceae) with the establishment of cell suspension culture ofPhyllanthusniruriL. 45-50.

7) Patel A., Singh P., \& Khan S .(2018) Comparative Studies on Phytochemical Analysis of Callus and Wild Plants of Phyllanthus niruri with Special Reference to Phyllanthin. UKJPB. 6(5): 17-23. https: //doi.org/10.20510/ukjpb/6/i5/177343

8) Sathya, A \& Ambikapathy , v. (2012). Studies on the phytochemistry, antibacterial activity and green synthesis of nanoparticles using Cassia tora I. against amphicillin resistant bacteria. Asian Journal of Plant Science and Research. 2 (4):486-489

9) Serunjogi, D. (2020). Active phytochemicals present in the Guava Tree (Psidium Guajava) leaf Extracts that grow in Uganda. Student's Journal of Health Research Africa, 1(12), 6. https://doi.org/10. 51168/sjhrafrica.v1i12.12

10) Serunjogi, D., \& Muwonge, K. (2020). Antimicrobial activity of Guava tree (Psidium Guajava) leaf extract and selected Commercial Antibiotics on Bacterial isolates from Kisubi Hospital. Student's Journal of Health Research Africa, 1(12), 10. https://doi. org/10.51168/sjhrafrica.v1i12.1

11) Trease G.E. \% Evans W.C. (1989): Phenols and Phenolic glycosides. Textbook of Pharmacognosy. 
Balliese, Tindall and Co Publishers, London 12:343383.

12) Virupanagouda P.P., Shivakumar H., Nanjappaiah H.M., Navanath K., Mohan C., \& Pandarinath. (2011). Phytopharmacology of Tephrosia purpurea Linn: An Overview. Pharmacologyonline 3: 11121140 https://pharmacologyonline.silae.it/files/new sletter/2011/vol3/112.patil.pdf

13) Viswanathan V.K, \& Hodges H. G. (2009). Enteric infection meets intestinal functional: how bacterial pathogens cause diarrhea" Nature Reviews. Microbiology 7 (2):110-9. https://doi.org/10.1038/n rmicro2053 PMid:19116615 PMCid:PMC3326399

14) Warren L., (2008) Lange Microbiology and Immunology Review>Chapter15.GramPositiveCocci10thedition>.

15) Washington (1970); Susceptibility tests; Agar dilution, in Linnette. American society of Microbiology, Pp. 967-971.

16) Wilem F. (2008) justicia flava South African National biodiversity institute http://pza.sanbi.org/ justicia-flava.

17) Yedjou, C. G., Izevbigie, E. B., \& Tchounwou, P. B. (2013). Vernonia amygdalina-Induced Growth Arrest and Apoptosis of Breast Cancer (MCF-7) Cells. Pharmacology \& pharmacy, 4(1), 10.4236/pp.2013.41013. https://doi.org/10.4236/p p.2013.41013 PMid:24353904 PMCid:PMC3864043 